\title{
Statin use and breast cancer recurrence in postmenopausal women treated with adjuvant aromatase inhibitors: a Danish population-based cohort study
}

\author{
Sixten Harborg ${ }^{1}$ [ $\cdot$ Uffe Heide-Jørgensen $^{2} \cdot$ Thomas P. Ahern $^{3} \cdot$ Marianne Ewertz $^{4} \cdot$ Deirdre Cronin-Fenton $^{2}$. \\ Signe Borgquist ${ }^{1,5}$
}

Received: 23 April 2020 / Accepted: 13 June 2020 / Published online: 22 June 2020

(c) The Author(s) 2020

\begin{abstract}
Purpose To examine the association between statin use and risk of breast cancer recurrence in a national Danish cohort of postmenopausal breast cancer patients receiving aromatase inhibitors (AI) in the adjuvant setting.

Patients and methods We enrolled all postmenopausal patients diagnosed with stage I-III estrogen receptor positive breast cancer during the years 2007-2017, assigned adjuvant AI treatment, and registered in both the Danish Breast Cancer Group database and the Danish Cancer Registry. We ascertained incident statin exposure ( $\geq 1$ prescription post-diagnosis) from the Danish National Prescription Registry and modeled statins as a time-varying exposure lagged by 6 months. Follow-up began 7 months after diagnosis and continued to the first event of recurrence, death, emigration, 5 years elapsed, or 25th September 2018. We estimated incidence rates of recurrence at 5 years and used Cox regression models to compute crude and adjusted hazard ratios (HRs) with 95\% confidence intervals (95\% CI), comparing statin exposure with non-exposure.

Results We enrolled 14,773 eligible patients. During the 5 years of follow-up, there were 32 recurrences in 3163 person-years of follow-up among statin-exposed patients, and 612 recurrences in 45,655 person-years among unexposed patients (incidence rate per 1000 person-years: 10.12 [95\% CI 6.92-14.28] and 13.40 [95\% CI 12.36-14.51], respectively). In multivariable models, any statin exposure was associated with a reduced rate of 5-year breast cancer recurrence (adjusted HR 0.72 [95\% CI 0.50-1.04]). Considering only lipophilic statins as exposure the results were similar (adjusted HR 0.70 [95\% CI 0.48-1.02]). Conclusions Statin use was associated with a reduced risk of breast cancer recurrence among postmenopausal patients diagnosed with early stage breast cancer who received adjuvant AI therapy.
\end{abstract}

Keyword Aromatase inhibitors $\cdot$ Cohort study $\cdot$ Endocrine therapy $\cdot$ Statins $\cdot$ Breast cancer

Electronic supplementary material The online version of this article (https://doi.org/10.1007/s10549-020-05749-5) contains supplementary material, which is available to authorized users.

Sixten Harborg

sixten.harborg@oncology.au.dk

1 Department of Oncology, Aarhus University Hospital/ Aarhus University, Entrance C, Level 1, C118, Palle Juul-Jensens Boulevard 99, 8200 Aarhus N, Denmark

2 Department of Clinical Epidemiology, Aarhus University, Aarhus N, Denmark

3 Department of Surgery, University of Vermont, Burlington, USA

4 Oncology Research Unit, Institute of Clinical Research, University of Southern Denmark, Odense C, Denmark

5 Department of Oncology and Pathology, Lund University, Lund, Sweden

$\begin{array}{ll}\text { Abbreviations } \\ \text { AI } & \text { Aromatase inhibitors } \\ \text { HR } & \text { Hazard ratio } \\ \text { CI } & \text { Confidence interval } \\ \text { CLM } & \text { Cholesterol-lowering medication } \\ \text { BCR } & \text { Breast cancer recurrence } \\ \text { ER+ } & \text { Estrogen receptor positive } \\ \text { DDD } & \text { Defined daily doses } \\ \text { DBCG } & \text { Danish Breast Cancer Cooperative Group } \\ \text { HER2 } & \text { Human epidermal growth factor receptor 2 } \\ \text { CRS } & \text { The Danish civil registration system } \\ \text { CPR } & \text { Civil personal registration } \\ \text { DNPR } & \text { Danish national patient registry } \\ \text { CCI } & \text { Charlson Comorbidity Index } \\ \text { NPR } & \text { The Danish national prescription registry } \\ \text { ATC } & \text { Anatomical therapeutic chemical } \\ \text { BMI } & \text { Body mass index }\end{array}$




\section{Introduction}

Cholesterol-lowering medication (CLM) is frequently prescribed for prevention of cardiovascular disease [1,2]. The most common cholesterol-lowering drugs are statins [1]. Statins are HMG-CoA reductase inhibitors, which block the rate-limiting step in the cholesterol biosynthesis [2]. Beyond this, statins may affect the incidence or severity of other diseases (e.g., cancer) by blocking the cholesterol synthesis pathway [3]. Apart from the reduction of systemic cholesterol levels through hepatic clearance, statins inhibit the mevalonate pathway in breast cancer cells, which may lower intracellular cholesterol synthesis and lead to reduced intratumoral autocrine hormone production, since cholesterol is required for the synthesis of all steroid hormones [4]. Statins may also indirectly influence tumor growth through reduced systemic levels of cholesterol and its metabolites, in particular 27-hydroxycholesterol, which acts as an estrogen receptor ligand [5-7]. Previous studies indicate an association between use of CLM and a reduced risk of breast cancer recurrence (BCR) [8]. Similarly, long-term post-diagnostic use of statins has been associated with reduced risk of contralateral breast cancer [9]. Among women with estrogen receptor positive $(E R+)$ breast cancer, statin use seems to have a favorable impact on BCR and mortality when combined with adjuvant endocrine treatment $[8,10-12]$. Lipophilic statins have been reported to have a more competent anticancer effect than hydrophilic statins [8, 13-17]. Since the publication of the earlier Danish study by Ahern et al. investigating the association between statin use and BCR, statin use has increased among Danish citizens from 23.8 defined daily doses (DDD) per 1000 inhabitants per day in 2003 to 144.6 DDD/1000 inhabitants/day in 2017 [18]. In Denmark, about 4700 women are diagnosed with breast cancer every year [19]. Given the increasing breast cancer incidence [19], any beneficial impact of statins on BCR among women treated for breast cancer could be of major value.

Aromatase inhibitors (AIs) have now been used as adjuvant therapy in postmenopausal, ER+ breast cancer patients for more than a decade. The commonly prescribed AIs, letrozole and anastrozole, both seem to increase the risk of developing hypercholesterolemia compared with tamoxifen $[20,21]$. Conversely, tamoxifen treatment decreases cholesterol levels by downregulation of cholesterol synthesis [10, 22]. Hypothetically, AI-mediated estrogen suppression may thereby be less effective in women with an excessive supply of precursor hormones (e.g., as in hypercholesterolemia) since this could potentially overwhelm the anti-aromatase activity. Because AIs have been recommended as standard adjuvant treatment in Denmark-sequentially together with tamoxifen since 2007 and alone since 2009-data collected over the past decade now permit studies of recurrence risk in patients treated with AIs. This study aims to update knowledge on the association between post-diagnostic statin use and BCR in a cohort of postmenopausal patients diagnosed with early stage breast cancer, including patients diagnosed and treated in the modern era of adjuvant therapy with AIs.

We hypothesize that statin use reduces the risk of BCR among women with breast cancer, and that the protective effect is most pronounced among lipophilic statin users.

\section{Patients and methods}

We conducted a nationwide, population-based cohort study using Danish clinical and administrative registries.

\section{Data sources}

The Danish Breast Cancer Cooperative Group's (DBCG) clinical database covers the entire Danish female population and includes data from 1977 with a completeness of more than 95\% [23]. Patient data are reported through standardized forms by all hospital parts of the Danish health care system involved in the diagnosis, treatment, and follow-up of breast cancer [24]. The information retrieved from the DBCG registry for this study included patient age, menopausal status at diagnosis, type of primary surgery (breastconserving surgery or mastectomy), histologic tumor type and grade, lymph node status, ER status, human epidermal growth factor receptor 2 (HER2) status, adjuvant therapy (chemotherapy, intended-to-treat endocrine therapy and radiotherapy), and clinical follow-up for recurrences. The Danish Civil Registration System (CRS) has collected data on the Danish population since 1968. The CRS is updated daily and records each person's civil personal registration (CPR)-number, date of birth, vital and migration status [25]. The Danish National Patient Registry (DNPR) was established in 1977 and includes data on hospital-admissions, -discharge, -emergency, and -outpatient visits [26]. For each hospital encounter, one action diagnosis and up to 20 other diagnoses are recorded [27]. From the DNPR, data on comorbid diseases present at time of surgery were obtained through linkage via the CPR-number and summarized using the Charlson Comorbidity Index (CCI) [28], with breast cancer and non-melanoma skin cancer excluded. The Danish National Prescription Registry (NPR) has collected information on filled prescriptions, including anatomical therapeutic chemical (ATC) codes and date of dispensing, at hospitals and pharmacies in Denmark since 1995. However, drugs supplied directly by hospitals e.g., AIs are not captured by the registry. The completeness of NPR is high [29]. All data sources could be linked at the individual level using a unique identifier assigned to all Danish residents at birth or immigration. 


\section{Study population}

We identified all postmenopausal women with an incident diagnosis of stage I-III ER+ breast cancer who were reported to the DBCG registry and registered in the Danish Cancer Registry between 2007 and 2017 (Fig. 1). We excluded patients who filled a dispensing of statins in the year preceding their breast cancer diagnosis. Patients were also required to be assigned to an endocrine therapy treatment protocol, per the DBCG database.

\section{Follow-up and statistical analysis}

Follow-up began 7 months after breast cancer surgery thereby ensuring patients who had undergone adjuvant chemotherapy and had begun adjuvant endocrine treatment. Follow-up continued until any invasive BCR as recorded by DBCG, contralateral breast cancer, other malignancies, death, 5 years of follow-up, emigration or the end of available follow-up data on 25 September 2018. Patients with these events were censored at the time of the event.

For a patient to be defined as statin user in the analyses, the patient had to fill a prescription of statins. A filled prescription was assumed to expose the individual for one year of treatment. If the patient went off treatment, a new prescription was required for the patient to become exposed again. All patients redeeming a prescription of statins in the year prior to diagnosis were excluded. Statin exposure during follow-up was characterized as a time-varying variable with a 6-month lag to allow biological latency [30]. For example, a person was followed from date of surgery and assumed to be exposed 6 months after filling a statin prescription. We computed incidence rates of BCR for statin exposed and unexposed, and crude and adjusted hazard ratios using Cox regression models. Only complete cases were included in the analysis. In the adjusted model, we included the following covariates: age at diagnosis, metformin, aspirin, exposure to pre-diagnostic menopausal hormone therapy, union for international cancer control, histological grade, CCI score, type of primary surgery, adjuvant chemotherapy, and radiotherapy. Like statins, metformin and aspirin were also included as time-varying covariates. Patients filling a dispensing of metformin and/or aspirin were exposed for a year, and exposure was lagged by half a year.

\section{Sensitivity analyses}

We conducted a series of sensitivity analyses regarding the exposure. First, we investigated our hypothesis of a more protective effect of lipophilic statins on BCR by only considering lipophilic statins as the exposure. In a further sensitivity analysis, we tried to limit

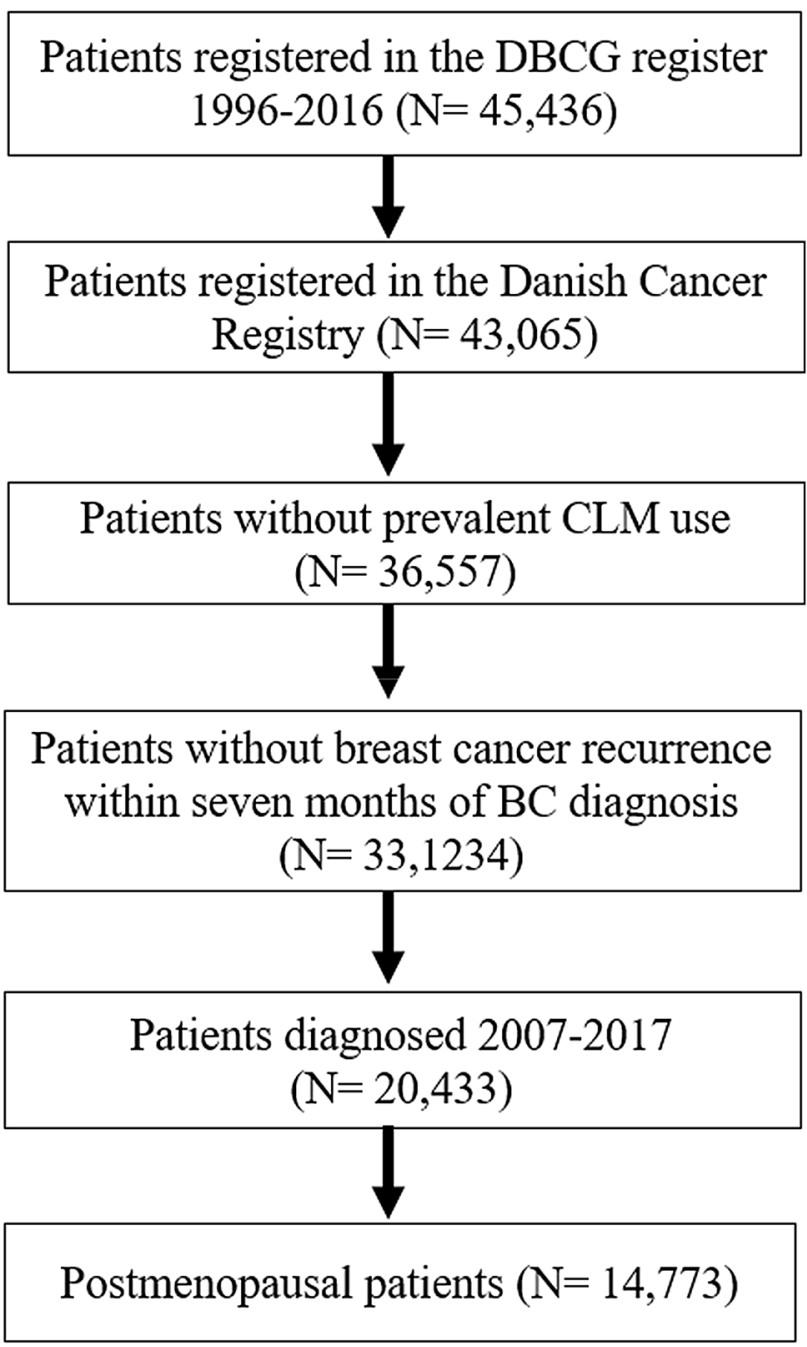

Fig. 1 Flowchart for breast cancer patients included in the final study population. DBCG Danish Breast Cancer Group, CLM cholesterollowering medication, $B C$ breast cancer. *Sequential treatment with Tamoxifen-Aromatase Inhibitors was recommended as standard adjuvant treatment in Denmark from 2007. In 2009, aromatase inhibitors alone became the up-front standard adjuvant treatment. **The Danish Cancer Registry is exclusively used to restrict the cohort to enable individual-level linkage with the Danish national patient registry and the Danish national prescription registry

misclassification of exposure in the exposed group by requiring patients to fill two prescriptions of statins in order for a subject to be classified as exposed. Finally, to examine possible differences in the association between any CLM use and breast cancer prognosis, we conducted the analyses including all types of CLM, that is, not restricted to statins. 


\section{Results}

In the cohort of 14,773 patients, median age at diagnosis was 65 years (interquartile range was 59-71 years). The median follow-up was 4.5 years and a total of 644 recurrences occurred (Table 1). Statins were prescribed to 1727 patients following breast cancer diagnosis. Most patients underwent breast-conserving surgery $(68.9 \%)$ while the rest had undergone mastectomy $(31.1 \%)$. At baseline, the CCI score was low for most patients. However, those who initiated statins during follow-up had more comorbidity and were older compared with non-users. Beyond this, incident statin users were more frequently assigned breast
Table 1 Patient and disease characteristics of postmenopausal women diagnosed with early stage breast cancer in Denmark from 2007-2017

\begin{tabular}{|c|c|c|}
\hline & Statin ever users, $N(\%)$ & Statin never users, $N(\%)$ \\
\hline Total & 1727 & 13,046 \\
\hline \multicolumn{3}{|l|}{ Age at diagnosis (years) } \\
\hline $30-39$ & $0(0.0)$ & $5(0.0)$ \\
\hline $40-49$ & $6(0.3)$ & $174(1.3)$ \\
\hline $50-59$ & $423(24.5)$ & 4007 (29.9) \\
\hline $60-69$ & $875(50.7$ & $5510(41.1)$ \\
\hline $70-79$ & $356(20.6)$ & $2614(19.5)$ \\
\hline $80+$ & $67(3.9)$ & $1094(8.2)$ \\
\hline \multicolumn{3}{|l|}{ UICC stage } \\
\hline I & $656(38.0)$ & $5247(39.1)$ \\
\hline II & $822(47.6)$ & $6093(45.4)$ \\
\hline III & $205(11.9)$ & $1606(12.0)$ \\
\hline Missing & 44 & 460 \\
\hline \multicolumn{3}{|l|}{ Type of primary surgery } \\
\hline Mastectomy & $494(28.6)$ & $4216(31.4)$ \\
\hline Breast-conserving surgery/lumpectomy & $1233(71.4)$ & 9190 (68.6) \\
\hline Adjuvant chemotherapy & $405(23.5)$ & $3976(29.7)$ \\
\hline Adjuvant radiotherapy & $672(38.9$ & $4036(30.1)$ \\
\hline Metformin & $306(17.7)$ & $327(2.4)$ \\
\hline Aspirin & $566(32.8)$ & $1355(10.1)$ \\
\hline Hormone replacement therapy & $1021(59.1)$ & $7698(57.4)$ \\
\hline \multicolumn{3}{|l|}{ Charlson Comorbidity Index score } \\
\hline None (score 0 ) & $1247(72.2)$ & $10,325(77.0)$ \\
\hline Mild (score 1-2) & $389(22.5$ & $2455(18.3)$ \\
\hline Severe (score $3+$ ) & $91(5.3)$ & $626(4.7)$ \\
\hline \multicolumn{3}{|l|}{ Histological grade } \\
\hline Grade 1 & $434(25.1)$ & $3173(23.7)$ \\
\hline Grade 2 & $898(52.0)$ & $7101(53.0)$ \\
\hline Grade 3 & $283(16.4)$ & $2147(16.0)$ \\
\hline Missing & 112 & 985 \\
\hline \multicolumn{3}{|l|}{ Histological type } \\
\hline Ductal & $1452(84.1)$ & $10,835(80.8)$ \\
\hline Lobular & $172(10.0)$ & $1701(12.7)$ \\
\hline Other/misisng & 103 & 870 \\
\hline \multicolumn{3}{|l|}{ HER2 } \\
\hline Normal & $1427(82.6)$ & $11,265(84.0)$ \\
\hline Overexpressed & $191(11.1)$ & $1521(11.3)$ \\
\hline Missing & 109 & 620 \\
\hline
\end{tabular}

UICC Union for International Cancer Control, CCI Charlson Comorbidity Index, HER2 human epidermal growth factor receptor 2

Follow-up ended at the 25th of September 2018

Non-lobular and non-ductal breast cancers are not histologically graded 
cancer conserving surgery and adjuvant radiotherapy. In addition, statin users were more likely to be treated with metformin $(N=306[17.7 \%])$ and aspirin $(N=566$ [32.8\%]) compared with non-users $(N=327$ [2.4\%]), $(N=1355$ [10.1\%]), respectively.

Table 2 displays the estimated hazard ratios in relation to statin use during the 5 years of follow-up. A total of 32 recurrences occurred during 3163 person-years of follow-up among women in the study population exposed to statins and 612 recurrences in 45,655 person-years in the unexposed group (incidence rate per 1000 personyears: 10.12 [95\% CI 6.92-14.28] and 13.40 [95\% CI 12.36-14.51], respectively). We observed a reduced risk of BCR associated with incident statin exposure (adjusted HR 0.72 [95\% CI 0.50-1.04]). The sensitivity analyses restricted to lipophilic statin use (Table 2) yielded similar findings (adjusted HR 0.70 [95\% CI 0.48-1.02]). The association held up among patients that filled two prescriptions of statins (adjusted HR 0.75 [95\% CI 0.51-1.11]), (Table 2). The association was not observed in analyses restricted to hydrophilic statin use (adjusted HR 0.73 [95\% CI 0.18-2.91]). Analyses not restricted to statins but including all types of CLM did not attenuate the association (adjusted HR 0.75 [95\% CI 0.53-1.07]) (Table 2).

\section{Discussion}

The results of this study show an association between post-diagnostic incident statin use and a reduction in risk of recurrence among patients diagnosed with early breast cancer and treated with aromatase inhibitors. Beyond this, the study also displays a reduction in risk of recurrence among these patients when exclusively exposed to lipophilic statins in accordance with earlier studies [8, 13]. This study, performed in a modern cohort of AI-treated breast cancer patients, supports the findings from earlier studies, based on predominantly tamoxifen-treated populations $[8,12,13$, 31-35].

In cancer cells, statins are associated with cell cycle disruption [36]. Statins exert pleiotropic effects through their ability to decrease levels of farnesyl pyrophosphate and geranylgeranyl pyrophosphate, thereby decreasing cellular signaling of G proteins [37], and restrain proliferation and survival of cancer cells [38]. Lipophilic statins diffuse across the plasma membrane in extrahepatic cells, thus disrupting cholesterol synthesis, whereas hydrophilic statins are largely confined to the liver [39]. This suggests that lipophilic statins can also affect breast cancer cells directly, whereas hydrophilic statins, solemnly affect breast cancer cells indirectly via alterations in systemic cholesterol levels [40]. The majority of statin users in this study were exposed to simvastatin and a large amount to atorvastatin, both regarded as being lipophilic statins. This is in accordance with our hypothesis, that lipophilic statins have a more competent anticancer effect. Nonetheless, it makes the generalizability of the association between statins in general and a reduced risk of BCR limited to the most commonly prescribed statins.

Considering the association of higher recurrence rates amongst overweight and obese women diagnosed with breast cancer [41, 42], and the associations between statins and overweight [43], it would have been of importance to account for body mass index as a confounder. Due to limited data access, this was unfortunately not possible. As no adjustment for BMI was made in the analyses of this study it may have impacted the results and made them more

Table 2 Number of recurrences and recurrence rates per 1000 person-years in relation to statin use after breast cancer surgery in postmenopausal women on AIs diagnosed in Denmark from 2007-2017

\begin{tabular}{|c|c|c|c|c|c|}
\hline Exposure & Person-years & Recurrences & $\begin{array}{l}\text { Incidence rate per } 1000 \\
\text { person-years }(95 \% \mathrm{CI})\end{array}$ & Hazard ratio $(95 \% \mathrm{CI})$ & $\begin{array}{l}\text { Adjusted hazard } \\
\text { ratio }(95 \% \mathrm{CI})\end{array}$ \\
\hline Not exposed to CLM & 45,596 & 610 & $13.38(12.34-14.48)$ & & \\
\hline CLM exposure & 3231 & 34 & $10.52(7.29-14.70)$ & $0.75(0.53-1.07)$ & $0.75(0.53-1.07)$ \\
\hline Not exposed to statins & 45,655 & 612 & $13.40(12.36-14.51)$ & & \\
\hline Statin exposure & 3163 & 32 & $10.12(6.92-14.28)$ & $0.72(0.50-1.03)$ & $0.72(0.50-1.04)$ \\
\hline Not exposed to lipophilic statins & 45,787 & 614 & $13.41(12.37-14.51)$ & & \\
\hline Lipophilic statin exposure & 3041 & 30 & $9.87(6.66-14.08)$ & $0.70(0.49-1.02)$ & $0.70(0.48-1.02)$ \\
\hline Not exposed to simvastatins & 46,506 & 619 & $13.31(12.28-14.40)$ & & \\
\hline Simvastatin exposure & 2231 & 25 & $10.77(6.97-15.90)$ & $0.78(0.52-1.16)$ & $0.73(0.48-1.10)$ \\
\hline Not exposed to atorvastatins & 48,000 & 639 & $13.31(12.30-14.39)$ & & \\
\hline Atorvastatin exposure & 827 & 5 & $6.05(1.96-14.11)$ & $0.44(0.18-1.05)$ & $0.54(0.22-1.31)$ \\
\hline
\end{tabular}

CI confidence interval, CLM cholesterol-lowering medication

Adjusted for; age at diagnosis; union for international cancer control; histological grade; adjuvant chemotherapy; type of primary surgery; radiotherapy; hormone therapy; metformin; aspirin 
imprecise compared to results adjusted for BMI. Another possible limitation to this study may be adherence to endocrine therapy. Non-adherence to adjuvant endocrine therapy is a clinically relevant concern, and several studies have observed the negative influence on clinical outcome [44]. The most critical factor to prevent discontinuation of endocrine therapy is reported to be patient contact [45]. In addition, adherence to statin therapy has been reported to be low in cardiovascular studies [46]. Moreover, patient contact has been highlighted as an important factor in adherence to statins [47]. Yet, discontinuation of statin therapy is often not permanent, and as many as $60 \%$ of the patients discontinuing statin therapy returns to their medication plan within 2 years [48]. Nonetheless, patients within this cohort, are closely monitored throughout their first 5 years of endocrine treatment after breast cancer diagnosis [49]. However, in this study it was not possible to control for accuracy of classification of adjuvant endocrine treatment-nor for adherence to therapy-as an intention-to-treat approach was used. Yet, studies in DBCG report high compliance in treatment patterns to the national guidelines [23]. Therefore we do not expect our results to be due to change in endocrine treatment, as this patient group is engaged in one type of endocrine treatment, and will change only if treatment is contraindicated [50].

Systemic cholesterol levels are associated with both risk [51] and prognosis [52] of breast cancer. As hypercholesterolemia is one of the main indications for a statin prescription [53], it could possibly induce confounding by indication to influence our results.

Another potential bias might be that higher cholesterol levels are a function of particularly robust response to AI therapy; however, earlier studies by us employed a marginal structural modeling to account for e.g., time-varying cholesterol levels, and the clinically beneficial associations between statin use and BCR held up [10].

The decreased risk of recurrence associated with statin use in our study may also be due to healthy user bias. However, in Denmark, statins are only available via prescription and a Danish study concluded that statin users are representative of the general Danish population [54], an inverse association is therefore unlikely. Unfortunately, no information on mammography screening history was available; therefore, statin users might induce surveillance bias if incident statin users were more prone to undergo breast cancer surveillance. This could also possibly induce lead-time bias by increasing the likelihood of breast cancer diagnosis at an earlier stage. However, our analyses were adjusted for disease stage.

In this study anyone redeeming a statin prescription in the year prior to diagnosis was excluded, a time-varying approach in modeling the analyses was used to eliminate immortal time bias and drug exposure was lagged by one year to avoid reverse causation [55]. Finally, we do not expect considerable residual confounding of our adjusted estimates since the associations were not affected by adjustment for factors associated with recurrence. Other factors than the ones adjusted for that should be strongly associated with both statin use and BCR is considered unlikely to exist.

Our study provide evidence for a reduced risk of recurrence associated with statin use among postmenopausal women with an early stage breast cancer who are treated with AIs. Taken together with previous studies [8], this study provides consistent consecutive association between statin use and a reduction in BCR over time in a high-quality database. These findings suggest that AI-treated, early stage breast cancer patients might benefit further from addition of a lipophilic statin to their adjuvant therapy regimen. This question warrants investigation in a properly randomized study to decide statins definite role in breast cancer. Prospective research should aim to investigate how statins can decrease the risk of BCR and cardiovascular diseases as a repercussion of breast cancer treatment with AIs.

\section{Conclusion}

In conclusion, our study confirms the previously reported recurrence benefit of statins in postmenopausal early breast cancer patients, studied for the first time in the modern AI treatment era. The evidence from this study supports further investigation of adjuvant statin therapy in a randomized clinical trial of breast cancer patients.

Author contributions Study concepts (SB, DCF, ME, TPA), study design (SH, SB, DCF, UHJ, TPA), statistical analyses (UHJ), interpretation of data (SH, SB, DCF, UHJ, TPA), manuscript preparation (SH \& SB), manuscript editing (SH), manuscript review (SB, DCF, UHJ, TPA, ME).

Funding This work was supported by Jeppe Juhls Mindelegat and Radiumstationen Research Grants.

Availability of data and materials The data that support the findings of this study are available from Danish Breast Cancer Cooperative Group, but restrictions apply to the availability of these data, which were used under license for the current study, and so are not publicly available. Data are however available from the authors upon reasonable request and with permission of Danish Breast Cancer Cooperative Group.

\section{Compliance with ethical standards}

Conflict of interest S.B. has received travel, accommodations, or expenses from Pfizer and Roche. None of this had any role in the design, data collection, analysis, or preparation of the manuscript. All remaining authors declare no conflicts of interest. 
Informed consent Informed consent to participate in the study was not deemed necessary according to national regulations.

Open Access This article is licensed under a Creative Commons Attribution 4.0 International License, which permits use, sharing, adaptation, distribution and reproduction in any medium or format, as long as you give appropriate credit to the original author(s) and the source, provide a link to the Creative Commons licence, and indicate if changes were made. The images or other third party material in this article are included in the article's Creative Commons licence, unless indicated otherwise in a credit line to the material. If material is not included in the article's Creative Commons licence and your intended use is not permitted by statutory regulation or exceeds the permitted use, you will need to obtain permission directly from the copyright holder. To view a copy of this licence, visit http://creativecommons.org/licenses/by/4.0/.

\section{References}

1. Goff DC, Lloyd-Jones DM, Bennett G, Coady S, D’Agostino RB, Gibbons R et al (2014) 2013 ACC/AHA guideline on the assessment of cardiovascular risk: a report of the American College of Cardiology/American Heart Association Task Force on Practice Guidelines. J Am Coll Cardiol 63(25 Pt B):2935-2959

2. Brown MS, Goldstein JL (1980) Multivalent feedback regulation of HMG CoA reductase, a control mechanism coordinating isoprenoid synthesis and cell growth. J Lipid Res 21(5):505-517

3. Zhou Q, Liao JK (2009) Statins and cardiovascular diseases: from cholesterol lowering to pleiotropy. Curr Pharm Des 15(5):467-478

4. Warner MGJA (2014) On estrogen, cholesterol metabolism, and breast cancer. N Engl J Med 370:572-573

5. McDonnell DP, Chang CY, Nelson ER (2014) The estrogen receptor as a mediator of the pathological actions of cholesterol in breast cancer. Climacteric. 17(Suppl 2):60-65

6. Wu QITSR et al (2013) 27-Hydroxycholesterol promotes cellautonomous. Cell Rep 5:637-645

7. Nelson WSEJJS et al (2013) 27-Hydroxycholesterol links hypercholesterolemia and breast cancer pathophysiology. Science 342:1094-1098

8. Ahern TP, Pedersen L, Tarp M, Cronin-Fenton D, Garne JP, Silliman RA et al (2011) Statin Prescriptions and Breast Cancer Recurrence Risk: A Danish Nationwide Prospective Cohort Study. JNCI J Natl Cancer Inst 103(19):1461-1468

9. Langballe R, Cronin-Fenton D, Dehlendorff C, Jensen MB, Ejlertsen B, Andersson M et al (2018) Statin use and risk of contralateral breast cancer: a nationwide cohort study. Br J Cancer 119(10):1297-1305

10. Borgquist S, Giobbie-Hurder A, Ahern TP, Garber JE, Colleoni M, Láng I et al (2017) Cholesterol, cholesterol-lowering medication use, and breast cancer outcome in the BIG 1-98 study. JCO 35(11):1179-1188

11. Nielsen SF, Nordestgaard B, Bojesen SE (2012) Statin use and reduced cancer-related mortality. N Engl J Med 367(19):1792-1802

12. Borgquist S, Broberg P, Tojjar J, Olsson H (2019) Statin use and breast cancer survival—a Swedish nationwide study. BMC Cancer 19(1):54

13. Kwan ML, Habel LA, Flick ED, Quesenberry CP, Caan B (2008) Post-diagnosis statin use and breast cancer recurrence in a prospective cohort study of early stage breast cancer survivors. Breast Cancer Res Treat 109(3):573-579

14. Campbell MJ, Esserman LJ, Zhou Y, Shoemaker M, Lobo M, Borman E et al (2006) Breast cancer growth prevention by statins. Can Res 66(17):8707-8714
15. Chan KKW, Oza AM, Siu LL (2003) The statins as anticancer agents. Clin Cancer Res 9(1):10-19

16. Katz MS (2005) Therapy insight: potential of statins for cancer chemoprevention and therapy. Nat Clin Pract Oncol 2:82

17. Kumar AS, Benz CC, Shim V, Minami CA, Moore DH, Esserman LJ (2008) Estrogen receptor-negative breast cancer is less likely to arise among lipophilic statin users. Cancer Epidemiol Biomark Prev 17(5):1028-1033

18. Schmidt M, Hallas J, Laursen M, Friis S (2016) Data resource profile: Danish online drug use statistics (MEDSTAT). Int J Epidemiol 45(5):1401-1402

19. Engholm G, Ferlay J, Christensen N, Bray F, Gjerstorff ML, Klint A et al (2010) NORDCAN-a Nordic tool for cancer information, planning, quality control and research. Acta Oncol 49(5):725-736

20. Thürlimann B, Keshaviah A, Coates AS, Mouridsen H, Mauriac L, Forbes JF et al (2005) A comparison of letrozole and tamoxifen in postmenopausal women with early breast cancer. N Engl J Med 353(26):2747-2757

21. Howell A, Cuzick J, Baum M, Buzdar A, Dowsett M, Forbes JF et al (2005) Results of the ATAC (Arimidex, Tamoxifen, Alone or in Combination) trial after completion of 5 years' adjuvant treatment for breast cancer. Lancet 365(9453):60-62

22. Gylling H, Pyrhönen S, Mäntylä E, Mäenpää H, Kangas L, Miettinen TA (1995) Tamoxifen and toremifene lower serum cholesterol by inhibition of delta 8-cholesterol conversion to lathosterol in women with breast cancer. JCO 13(12):2900-2905

23. Cronin-Fenton D, Kjærsgaard A, Ahern TP, Mele M, Ewertz M, Hamilton-Dutoit $S$ et al (2017) Validity of Danish Breast Cancer Group (DBCG) registry data used in the predictors of breast cancer recurrence (ProBeCaRe) premenopausal breast cancer cohort study. Acta Oncol 56(9):1155-1160

24. Møller S, Jensen M-B, Ejlertsen B, Bjerre KD, Larsen M, Hansen HB et al (2008) The clinical database and the treatment guidelines of the Danish Breast Cancer Cooperative Group (DBCG); its 30-years experience and future promise. Acta Oncol 47(4):506-524

25. Pedersen CB (2011) The Danish civil registration system. Scand J Public Health 39(7 Suppl):22-25

26. Schmidt M, Schmidt SAJ, Sandegaard JL, Ehrenstein V, Pedersen L, Sørensen HT (2015) The Danish National Patient Registry: a review of content, data quality, and research potential. Clin Epidemiol 7:449-490

27. Lynge E, Sandegaard JL, Rebolj M (2011) The Danish National Patient Register. Scand J Public Health 39(7_Suppl):30-33

28. Charlson ME, Pompei P, Ales KL, MacKenzie CR (1987) A new method of classifying prognostic comorbidity in longitudinal studies: development and validation. J Chron Dis 40(5):373-383

29. Pottegård A, Schmidt SAJ, Wallach-Kildemoes H, Sørensen HT, Hallas J, Schmidt M (2017) Data resource profile: the Danish National Prescription Registry. Int J Epidemiol 46(3):798

30. Tamim H, Monfared AAT, LeLorier J (2007) Application of lag-time into exposure definitions to control for protopathic bias. Pharmacoepidemiol Drug Saf 16(3):250-258

31. Boudreau DM, Yu O, Chubak J, Wirtz HS, Bowles EJA, Fujii M et al (2014) Comparative safety of cardiovascular medication use and breast cancer outcomes among women with early stage breast cancer. Breast Cancer Res Treat 144(2):405-416

32. Murtola TJ, Visvanathan K, Artama M, Vainio H, Pukkala E (2014) Statin use and breast cancer survival: a nationwide cohort study from Finland. PLoS ONE 9(10):e110231

33. Nickels S, Vrieling A, Seibold P, Heinz J, Obi N, Flesch-Janys D et al (2013) Mortality and recurrence risk in relation to the use of lipid-lowering drugs in a prospective breast cancer patient cohort. PLoS ONE 8(9):e75088 
34. Chae YK, Valsecchi ME, Kim J, Bianchi AL, Khemasuwan D, Desai A et al (2011) Reduced risk of breast cancer recurrence in patients using ACE inhibitors, ARBs, and/or statins. Cancer Invest 29(9):585-593

35. Cardwell CR, Hicks BM, Hughes C, Murray LJ (2015) Statin use after diagnosis of breast cancer and survival: a population-based cohort study. Epidemiology 26(1):68-78

36. Demierre M-F, Higgins PDR, Gruber SB, Hawk E, Lippman SM (2005) Statins and cancer prevention. Nat Rev Cancer 5:930

37. Stancu C, Sima A (2001) Statins: mechanism of action and effects. J Cell Mol Med 5(4):378-387

38. Mullen PJ, Yu R, Longo J, Archer MC, Penn LZ (2016) The interplay between cell signalling and the mevalonate pathway in cancer. Nat Rev Cancer 16:718

39. Schachter M (2005) Chemical, pharmacokinetic and pharmacodynamic properties of statins: an update. Fundam Clin Pharmacol 19(1):117-125

40. Ahern TP, Lash TL, Damkier P, Christiansen PM, Cronin-Fenton DP (2014) Statins and breast cancer prognosis: evidence and opportunities. Lancet Oncol 15(10):e461-e468

41. Lee K, Kruper L, Dieli-Conwright CM, Mortimer JE (2019) The impact of obesity on breast cancer diagnosis and treatment. Curr Oncol Rep 21(5):41

42. Sestak I, Distler W, Forbes JF, Dowsett M, Howell A, Cuzick J (2010) Effect of body mass index on recurrences in tamoxifen and anastrozole treated women: an exploratory analysis from the ATAC trial. J Clin Oncol 28(21):3411-3415

43. Zalesin KC, Franklin BA, Miller WM, Peterson ED, McCullough PA (2011) Impact of obesity on cardiovascular disease. Med Clin North Am 95(5):919-937

44. Makubate B, Donnan PT, Dewar JA, Thompson AM, McCowan C (2013) Cohort study of adherence to adjuvant endocrine therapy, breast cancer recurrence and mortality. Br J Cancer 108(7):1515-1524

45. Ziller V, Kyvernitakis I, Knöll D, Storch A, Hars O, Hadji P (2013) Influence of a patient information program on adherence and persistence with an aromatase inhibitor in breast cancer treatment-the COMPAS study. BMC Cancer 13:407

46. Hirsh BJ, Smilowitz NR, Rosenson RS, Fuster V, Sperling LS (2015) Utilization of and adherence to guideline-recommended lipid-lowering therapy after acute coronary syndrome: opportunities for improvement. J Am Coll Cardiol 66(2):184-192
47. Stacy JN, Schwartz SM, Ershoff D, Shreve MS (2009) Incorporating tailored interactive patient solutions using interactive voice response technology to improve statin adherence: results of a randomized clinical trial in a managed care setting. Popul Health Manag 12(5):241-254

48. Brookhart MA, Patrick AR, Schneeweiss S, Avorn J, Dormuth C, Shrank W et al (2007) Physician follow-up and provider continuity are associated with long-term medication adherence: a study of the dynamics of statin use. Arch Intern Med 167(8):847-852

49. Jensen M-B, Laenkholm A-V, Offersen BV, Christiansen P, Kroman N, Mouridsen HT et al (2018) The clinical database and implementation of treatment guidelines by the Danish Breast Cancer Cooperative Group in 2007-2016. Acta Oncol 57(1):13-18

50. Mouridsen H, Giobbie-Hurder A, Goldhirsch A, Thürlimann B, Paridaens R, Smith I et al (2009) Letrozole therapy alone or in sequence with tamoxifen in women with breast cancer. N Engl J Med 361(8):766-776

51. Martin LJ, Melnichouk O, Huszti E, Connelly PW, Greenberg CV, Minkin S et al (2015) Serum lipids, lipoproteins, and risk of breast cancer: a nested case-control study using multiple time points. JNCI J Natl Cancer Inst 107(5):32

52. Ha M, Sung J, Song Y-M (2009) Serum total cholesterol and the risk of breast cancer in postmenopausal Korean women. Cancer Causes Control 20(7):1055-1060

53. Mach F, Baigent C, Catapano AL, Koskinas KC, Casula M, Badimon L et al (2020) 2019 ESC/EAS Guidelines for the management of dyslipidaemias: lipid modification to reduce cardiovascular risk. Eur Heart J 41(1):111-188

54. Thomsen RW, Nielsen RB, Nørgaard M, Horsdal HT, Stürmer $\mathrm{T}$, Larsen FB et al (2013) Lifestyle profile among statin users. Epidemiology 24(4):619-620

55. Lévesque LE, Hanley JA, Kezouh A, Suissa S (2010) Problem of immortal time bias in cohort studies: example using statins for preventing progression of diabetes. BMJ 340:b5087

Publisher's Note Springer Nature remains neutral with regard to jurisdictional claims in published maps and institutional affiliations. 